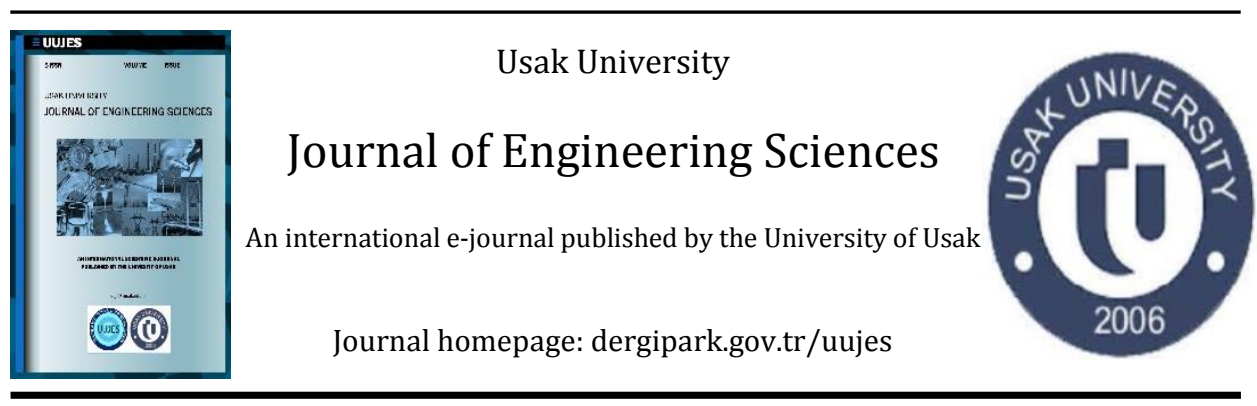

Research article

\title{
COMPARISON OF STRUCTURAL AND PHYSICAL PROPERTIES OF PES SHEATED PA AND PES DOUBLE BRAIDED ROPE LANYARDS USED IN WORKING AT HEIGHT
}

\author{
Fulya Yılmaz ${ }^{*}$, Mevlüt Tercan ${ }^{b}$ \\ ${ }^{a}$ Department of Textile Engineering, Graduate Education Institute, Uşak University, Uşak, Turkey \\ ${ }^{b}$ Department of Textile Engineering, Engineering Faculty, Uşak University, Uşak, Turkey
}

\begin{abstract}
Today occupational health and safety has become an important issue. Working at height is one of the important matters in occupational health and safety. When working at height, it is important to use protective equipments. Some of the important ones are working ropes and positioning lanyards. There is various type of lanyards. According to manner of work, lanyards are selected according to the standards. In this context, general information will be given about ropes suitable for working at height. According to market research, most used lanyards were selected and by changing some parameters of production, lanyards that had various properties were produced. Their mechanical and structural properties were tested.
\end{abstract}

Keywords: Occupational health and safety; working at height; fiber ropes; double braided ropes; lanyard.

(C)2021 Usak University all rights reserved.

\section{Introduction}

The work done in various areas where there is a level difference and the possibility of injury as a result of falling; is considered to be working at height [1]. Falling from a height is the main cause of fatal work accidents in the world. Working at height comprises various areas such as power lines, base stations, bridges, dams, shipyards, constructions,

\footnotetext{
*Corresponding author: Fulya Yılmaz

E-mail: fulya.ozdemir@usak.edu.tr (ORCID: 0000-0003-1242-0515)
} 
airports, forestry, exterior building maintenance, factories, playgrounds [2]. Working at height can be long-term or short-term. The work that will require working at height must be determined and precautions should be taken by making a risk assessment [3]. In the use of personal protective equipment (PPE), priority should be given to anti-fall motion restraint systems before the fall arrest systems that limit the distance or consequences of a fall. The selection of PPE must comply with the conditions required by the work, meet the relevant standard in accordance with the intended use, the components must have compatible components that they shouldn't affect each other's safety function [4].

Ropes are the materials used to connect employees, materials and their systems. In addition to being used as a basic material in rope access systems, it is used in various ways in personal protection systems and equipment against fall [2]. Rope structures are generally divided into two groups as strand and braided ropes (Fig. 1). These ropes have various uses. Rope is defined according to TS EN ISO 1968 standard as: "It is the part of a cord that is more than about $4 \mathrm{~mm}$ in diameter, and twisted or braided from three or more strands, or knitted around a core, or using plastic film layer around as cover". The structure of the rope consist of strands that are helically wrapped around a core, and the core in the center of the rope, which acts as a support for the strands. These yarns, strands and core are knitted in different structures creating different rope features [5].

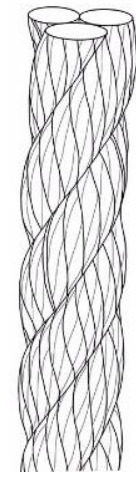

(a)

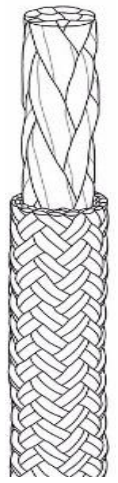

(b)

Fig. 1 Various type of ropes (a) three stranded rope (b) Double braided rope [6]

Double braided ropes have core and outer sheath (Fig. 1). After the core is braided, the outer sheath is knitted around the core layer. The outer sheath is produced in a braiding machine with more carriers. The number of carrier dummies varies depending on the rope diameter. Tension in the rope is shared by the sheath and core layer [7]. It is ergonomic in terms of attitude. It is strong and durable. It is possible to give the rope different characteristics. For example, it is possible to knit a heat-resistant outer sheath over the strong core [8]. It is easy to hold, flexible, less prone to curling and twisting than stranded ropes. The double braided outer sheath may tear when there is some loss of strength [9]. These kinds of ropes are soft and flexible. The disadvantage is when the core layer exposed to contamination or sand particulates, it will be prone to abrasion [10].

Most double layers of braided ropes can be made entirely of polyamide or polyester, or a mixture thereof. The use of high modulus fiber is rarely preferred because it can cause an unbalanced load distribution between the outer sheath and the core layer. In order to provide high strength, it is possible to obtain high strength hybrid structure by making 
the core layer of polyamide and outer sheath polyester. Elongation of the core layer causes the outer sheath to take up a large part of the tension in the string [7].

Fiber ropes made of polyester have good tensile strength and low elongation (lower than polyamide). UV resistance, salt water resistance, abrasion resistance are good in both dry and wet conditions in terms of both physical and chemical conditions. However, dynamic energy absorption capacity is lower than polyamide ropes $[8,11]$. It is resistant to axial pressure fatigue [12]. Depending on the construction structure, it can change the rope strength by $30 \%$. Pre-stretching is applied to prevent it from extending during use. If a lot of loading is made and the rope is used for a long time, it becomes a hard structure [9].

Polyamide ropes have high elongation as well as high breaking strength. The elongation at break is between $15-28 \%$. It is especially used in absorbing shock loads. The abrasion resistance of polyamide in wet state is worse than in dry state $[10,12]$. If it stays for a long time under humid conditions, the rope may become stiff. However, UV resistance is lower compared to PES [8]. When exposed to sunlight for a long time, its strength decreases. [11]. It is slightly more resistant than polyester with similar construction structure. It stretches approximately twice as much. When it is compared in terms of cost, it is between polyester and polypropylene's price. In today's synthetic ropes, there is generally no strength problem. The main problem is elongation. As the rope strength increases, the amount of elongation decreases [9]. Polyamide is resistant to rotting, oils, grease and many chemicals. It has high abrasion resistance [13]. However, when the rope is wet, the balance between the core layer and the outer sheath will change as the polyamide will contract and shorten, resulting in a problem in strength [7]. Operation up to high temperatures is possible $\left(480^{\circ} \mathrm{C}\right)[10]$.

It is possible to produce ropes in different patterns. The most used patterns are $1 / 1$ plain or diamond pattern, 2/2 regular (twill) pattern and 3/3 hercules pattern (Fig. 2).

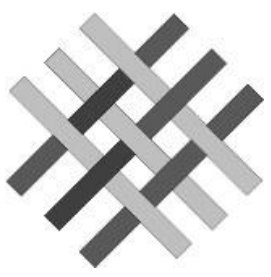

(a)

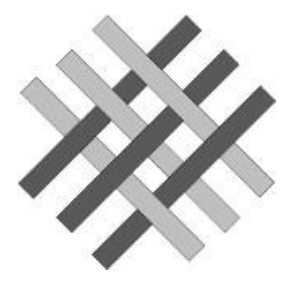

(b)

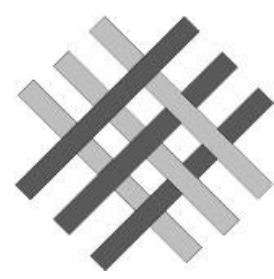

(c)

Fig. 2 Braid patterns (a)Diamond, (b)Regular, (c)Hercules [14]

Lanyard is a specially designed rope, strap or thick woven ribbon that connects to body harness, anchorage, deceleration device or safety rope (Fig. 3). Lanyards can be produced from double braided, kernmantel ropes as either produced from strap or thick ribbon. It is preferred that the lanyard is at the arm length of the employee. If the working point is at a longer distance, adjustable lanyards are used [2]. There are various type of materials used in lanyards; static fiber ropes, dynamic fiber ropes, webbings, wire ropes. It is necessary to choose lanyards with suitable ropes against the risks of the work area (hot surfaces, hot works, sharp surfaces, mechanical hazards [15].

Generally, lanyards are divided into two groups according to their intended use in working at heights. These are fall arrest lanyards (TS EN 354) and fall restraint lanyards 
(TS EN 358). Rope lanyards are generally composed of double braided or kernmantel fiber ropes, carabiners, shock absorbers, connectors [15].

Fall arrest lanyards, including the carabiner and shock absorbers on it, should be at least two meter. Lanyard lengths generally vary between $115-200 \mathrm{~cm}$. Shock absorbers should be on the fall arrest lanyards to reduce the negative effects of the forces on employee resulting from the fall. Fall arrest lanyards are available in two types as single arm (I Lanyard) or double arm (Y Lanyard) [15].

Fall restraint lanyards help the employee, in the work area by freeing both hands. These type of lanyards are not suitable for use to stop falling, they prevent an employee from getting close to the edge of the working platform or in other words it should be short enough to keep user in the safe distance in such a way that there is no possibility of falling from a height [15]. Unlike fall arrest lanyards, it is not necessary to use energy absorbers in fall restraint lanyards. In some cases, it can be used to limit falls. It is obligated to be connected to a fall arrest system (fall arrest lanyard or lifeline) when using fall restraint lanyards $[15,16,17]$. Work positioning equipment, in other words fall positioning systems, are under the category of fall prevention. But they are same as with the fall restraint system. A work positioning systems are used for vertical surfaces (walls or hydro poles). Different types of working positioning systems are available on the markets, but generally they are consisted of an adjustment device connected to the worker's harness at one hip. A work positioning system will be integrated into other fall arrest systems [18].

It is important to select the right lanyard according to its various characteristics like fall distance calculation, lanyard length, shock absorber opening length, employee's height, safety distance, one/two armed or adjustable lanyard, appropriate carabiners, compatibility with fall prevention and stopping systems. After selection of the suitable lanyard, other important point is inspection of lanyard before use against cuts, abrasions, broken stitching, swelling, unusual patterns, fraying, burns, chemical damage, weld spatter, discolouration $[15,19]$. All equipments should be stored in a cool and dry place and they are not subjected to direct sunlight [20].

When various companies' catalogues are examined $[21,22,23,24]$, fiber ropes that are used in lanyards are generally produced from low stretch or dynamic ropes and double braided or kernmantel form according to EN 1891 test standard. According to EN 1891 standard, low stretch kernmantel ropes are defined as a rope for use by people in rope access and all kinds of work positioning and restraint. The core is usually the main load bearing element and typically consists of parallel elements which have been pulled and twisted together in single or several layers, or of braided elements [25]. As a whole with other mentioned elements (connectors, energy absorbers, waist belt), they are evaluated according to EN 354, EN 355 and 358 test standards. It is important that rope lanyards should sustain a force at least $22 \mathrm{kN}$ according to TS EN 354 test standard. 


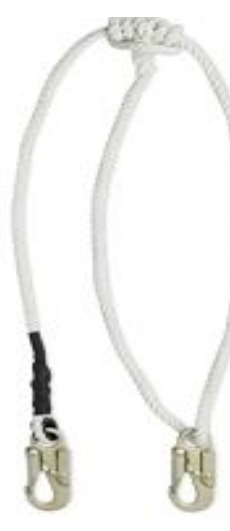

(a)

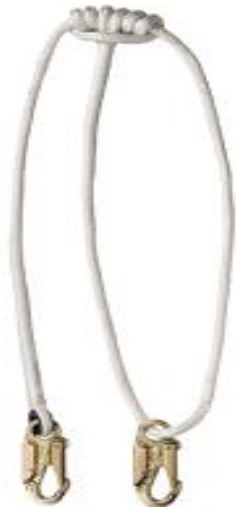

(b)

Fig. 3 (a) Stranded rope lanyard (b) Double braided lanyard [26, 27]

\section{Materials and Method}

In this study, it was aimed to produce low stretch double braided fiber ropes that are used in lanyards and test their physical and structural properties according to TS EN 1891 and TS EN 2307. These double braided ropes were produced with 1260 denier polyamide(PA) and 1500 denier polyester (PES) multifilament yarns. Double braided ropes are consisted of core and sheath as mentioned before. Core rope is the load bearing part of double braided ropes. In the first stage, core and sheath yarns are prepared individually before braiding process. Doubling process was performed (Fig. 4). PA and PES multifilaments were wounded on bobbins as seven plied for core part of ropes and as 17 plied for sheath part of ropes. After this process, bobbins were placed in a braiding machine with 16 carriers (Fig. 5). This braided core rope were placed in the center of the braiding machine with 32 carriers (Fig. 6). By pulling of the core layer from upper part of the braiding machine, sheath layer was braided onto the core layer. So double braided ropes were produced by this way.

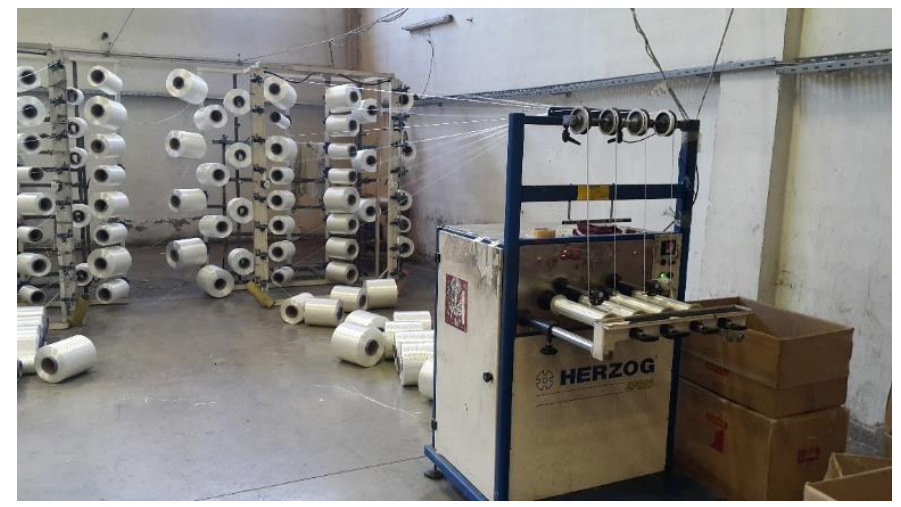

Fig. 4 Doubling process of fibre core and sheath parts of fibre ropes 


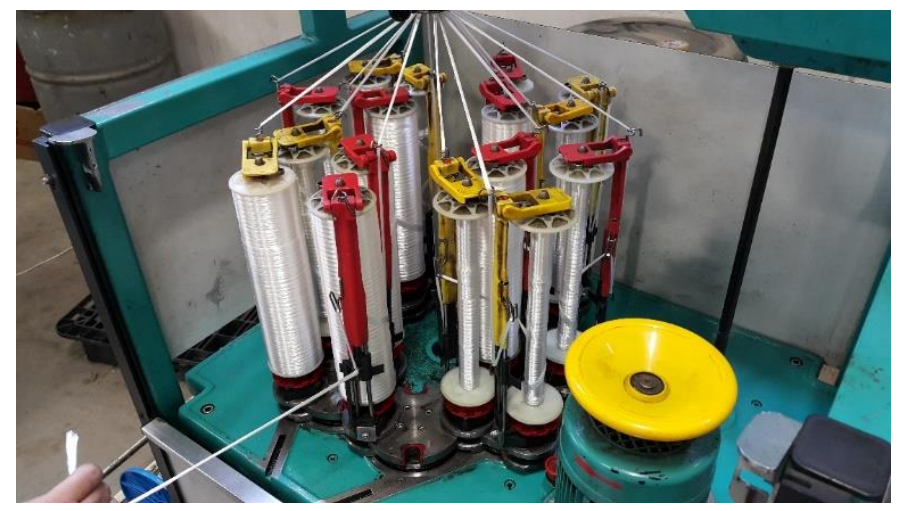

Fig. 5 Braiding core layer of fibre ropes

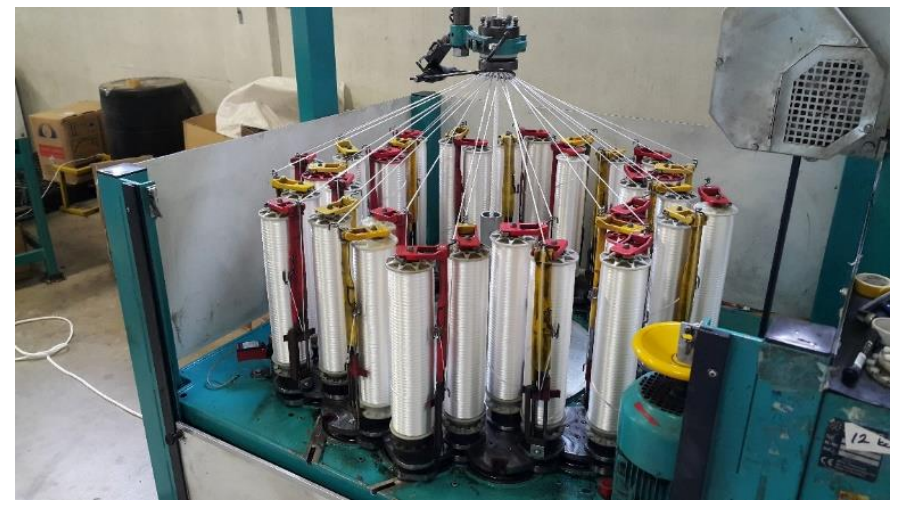

Fig. 6 Braiding sheath layer of fibre ropes

In Table 1, produced samples were classified as core and sheath part of fibre ropes. Samples were evaluated in two groups. The first group has PA core and PES sheath. Second group has PES core and PES sheath. Both groups were individually produced with same parameters as gear type and pattern. Two different gear types were used as 26 and 30 for producing tight and loose ropes (when compare with tight ones). $1 / 1$ and 2/2 braided rope patterns were preferred for production of fiber rope lanyards. 
Table 1. Produced samples of double braided ropes

\begin{tabular}{clllll}
\hline Group No & Samples & Core & Sheath & Gear & Pattern \\
\hline \multirow{2}{*}{1} & 1 & PA & PES & 26 & $1 / 1$ \\
& 2 & PA & PES & 30 & $1 / 1$ \\
& 3 & PA & PES & 26 & $2 / 2$ \\
& 4 & PA & PES & 30 & $2 / 2$ \\
\hline \multirow{2}{*}{2} & 5 & PES & PES & 26 & $1 / 1$ \\
& 6 & PES & PES & 30 & $1 / 1$ \\
& 7 & PES & PES & 26 & $2 / 2$ \\
& 8 & PES & PES & 30 & $2 / 2$ \\
\hline
\end{tabular}

Physical and structural properties are given in Table 2. All braided ropes were conditioned in standard atmospheric conditions $\left(20 \pm 2^{\circ} \mathrm{C}, 65 \pm 2 \%\right.$ relative humidity for 24 hrs) before testing. Samples were tested according to TS EN ISO 2307, TS EN 1891 test standard to determine diameter, pitch length, knotability, breaking force. Diameter results were measured with Mitutoyo Absolute AOS Digimatic caliper as standed in the standard. Pitch length $(\mathrm{mm})$ is the the distance that when the strand acts helically and aligns in the same point. Braid angle is the angle between longitudinal axis (y axis) and bias direction (on insertion of strands way) as shown in Fig. 7. Knotability is measured with tapered plug gauge to get internal diameter of the knots. It can be calculated as the rate of internal diameter of ropes to average of outer rope diameter according to TS EN 1891. Total unit mass is measured with core and sheath parts of fibre ropes for a meter. Breaking force test was carried out at a speed of $250 \pm 50 \mathrm{~mm} / \mathrm{min}$ on Zwick/Roell Z100 static testing device. According to TS EN 2307 Results were given in kN and also elongation at break values was calculated.

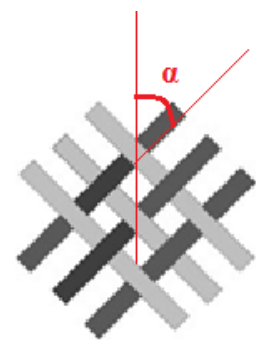

Fig. 7 Braid angle $(\alpha)$ 
Table 2. Physical and structural properties of double braided ropes

\begin{tabular}{|c|c|c|c|c|c|c|c|c|c|c|c|c|}
\hline \multirow{3}{*}{1} & 1 & Diamond & PA & PES & 12.53 & 36.59 & 33.1 & 1.59 & 111.99 & 46.9 & 29.10 & 29.64 \\
\hline & 3 & Regular & PA & PES & 12.12 & 38.07 & 35.1 & 1.65 & 111.00 & 46.9 & 32.32 & 29.52 \\
\hline & 4 & Regular & PA & PES & 12.15 & 43.45 & 37.7 & 0.74 & 109.44 & 48.9 & 27.54 & 30.67 \\
\hline \multirow{3}{*}{2} & 6 & Diamond & PES & PES & 12.54 & 39.07 & 37.8 & 0.72 & 118.66 & 53.3 & 25.96 & 28.51 \\
\hline & 7 & Regular & PES & PES & 12.14 & 37.45 & 34.7 & 1.65 & 122.42 & 51.4 & 15.93 & 26.64 \\
\hline & 8 & Regular & PES & PES & 12.32 & 44.44 & 37.2 & 0.97 & 121.14 & 53.3 & 25.75 & 28.12 \\
\hline
\end{tabular}




\section{Research Findings and Discussion}

\section{Diameter}

It is one of the important parameters for fibre ropes for choosing the right one. Because of its cross sectional changes can be appear, fiber ropes are loaded with weigh according criteria based on EN 1891 and then measured. For static ropes, diameter of fibre ropes should be between $8.5 \mathrm{~mm}$ and $16 \mathrm{~mm}$. When diameter results were compared for each 2 groups, for the first group that was PA cored and PES sheated ones, diamond patterned braided ropes had higher diameter results than the regular ones. Because of one strand on another group of strands, coarser fiber ropes were produced. It was the same for other group that is PES cored and PES sheated fiber ropes.

\section{Braid Angle}

Braid angle of the fiber ropes varies between $30^{\circ}-80^{\circ}$. All of the samples were included in the reference interval. Braid angle was measured as shown in Fig. 7. It depends on take up speed of the mandrel. With using two different gears (26 and 30), take up speed was changed. When using 26 gear for take up mechanism, low take up rate was obtained. On the other hand, higher take up rate was provided with 30 gear. The braid angles interval for samples 26 gear used ones (sample number $1,3,5,7$ ) were between $36^{\circ}-38^{\circ}$. For 30 gear used ones' braid angles were varied between $39^{\circ}-44^{\circ}$.

\section{Pitch length}

When it was checked and evaluated, the results of pitch length for each group in terms of number of gear teeth, pitch length or in other words lay length was also increased due to take up rate raise. This situation was relevant for also second group. Ömeroğlu also stated that if the pattern was kept constant, as braid angle increased, the pick count increased as well [28].

\section{Knotability}

Knot retention is important factor for the knots required works like mountain climbers, arborists, rescue crews and employess who work at height for multi purposes. According to TS EN 1891 standard, knotability should be below 1.2. For the first group of samples, in PA cored, PES sheated; diamond and also regular patterned double braided samples, it was difficult to make knots with 26 gear. Because, braided fiber ropes were tighter than other samples in this group. For second group, PES cored, PES sheated, regular patterned fibre ropes are much tighter so it is hard to make knots with this type of ones and so its knotability was above the reference level.

\section{Total mass}

For total mass that comprised from core and sheat parts of fibre ropes, second group had higher mass, because of used number of PES multifilament yarns. But here, it was important to percentage of core and sheath layers mass for meter. In TS EN 1891, the minimum percentage values were given in the formula according to fiber ropes diameter. Our samples were compatible with the required values. 


\section{Breaking strength}

In industrial catalogues for fiber ropes, usually breaking strength values were given $\mathrm{kN}$ unit, so this unit also used in this research. Results of breaking strength values were given in Fig. 8. For the first group, regular patterned; PA cored and PES sheated fiber ropes with 26 teeth gear had the highest breaking strength results. For second group, PES sheated and PES cored and diamond patterned fiber ropes had the highest results. But there wasn't so much difference in breaking strength values, with regular patterned fiber ropes with 30 gear teeth. Sample 5 and sample 7 that were PES sheated and PES cored, regularly, diamond and regular patterned with 26 teeth gear were under the reference level that is $22 \mathrm{kN}$ at least according to TS EN 1891.

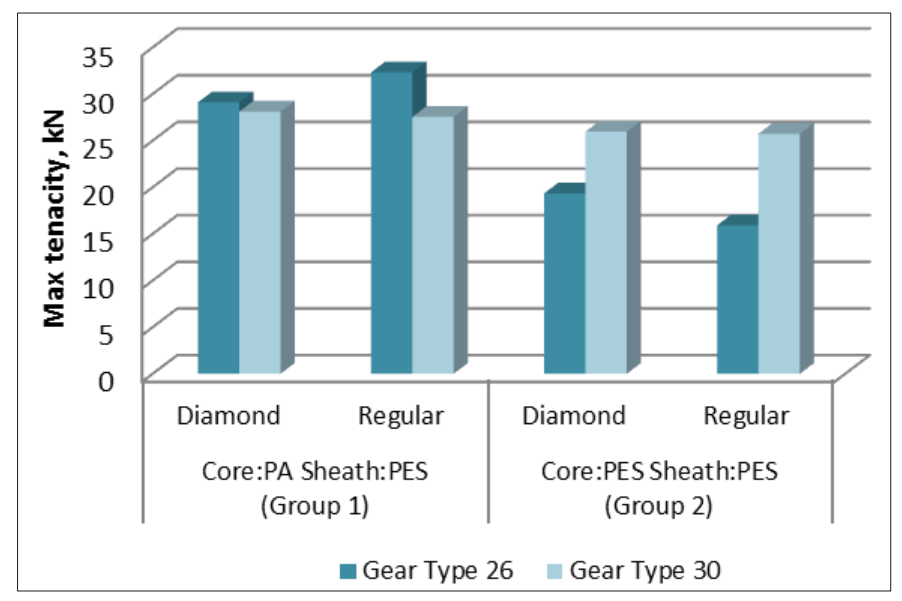

Fig. 8 Breaking strength of fiber ropes' results

\section{Elongation at break}

Other important parameter is elongation at break, values were given as percentage. In the first group, It could be seen that regular patterned samples had higher elongation at break values. For gear type 26 , the results were much closer compared in terms of gear type 30. For second group, when gear type changed to 30 , elongation at break values were increased (Fig. 9). 


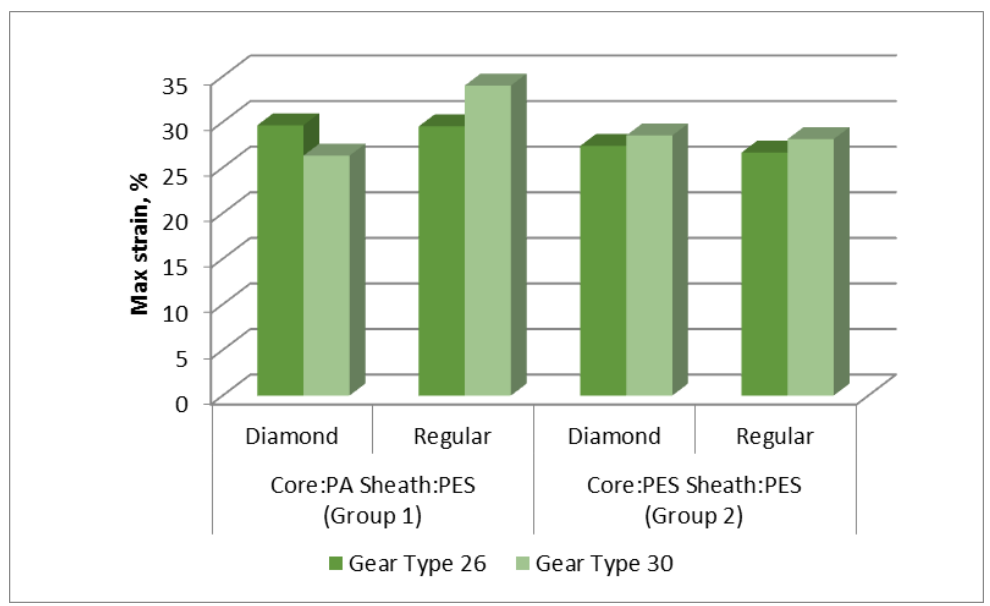

Fig. 9 Elongation at break values

\section{Conclusions}

In this study, physical and structural properties of double braided rope lanyards were evaluated. According to type of material, designed pattern and take up speed arranged with different gears, affected important parameters of double braided ropes as braid angle, knotability and breaking force. Generally braid angle and pitch length were effected by the change in take up speed. When take up speed was increased with 30 gears that was changed by 26 gears, braid angle was increased as well. Pitch length was also changed by the type of gears used. It was also increased when the take up speed was higher by using 30 gears. This situation is valid and important point for both groups. Knotability is also important factor while using lanyards. For the first group, regular and diamond patterned and produced with 26 gear ropes' knotability values were above the reference level. This means it is hard to make knots with this type of ropes due to their tight structural property. For second group, regular patterned and produced with 26 gear type of ropes' knotability value was above like in the first group. Breaking force is one of the most important factors, for the first group due to its tight structural and elasticity property becaused of used PA, samples 1 and 3 had the highest results. But their knotability was not sufficient for using. So the most suitable one is, diamond patterned and produced with 30 gear and sample numbered 3. For second group, diamond patterned and produced with 30 gear got the most highest result. Used as lanyard, structural and physical properties of ropes are so important and should be selected according to as mentioned properties. Also the dynamic tests should be taken. For the second part of this study, it is aimed to get the dynamic results of sample ropes.

\section{Acknowledgement}

This work has been supported by the Usak University Scientific Research Project under grant [2017/TP029]. 


\section{References}

1. Republic of Turkey Ministry of Family Labour and Social Services. Regulation on Occupational Health and Safety in Construction Works. [Document on the Internet]. 2013 [Cited 2019 June 10]. Available from: https://www.mevzuat.gov.tr/mevzuat?MevzuatNo=18928\&MevzuatTur=7\&Mevzuat Tertip $=5$

2. No Fall Project (EU Project work). Yüksekte çalışma iş güvenliği için yeni bir proaktif eğitim programı (Translation: A new proactive training program for work safety at height). No Fall Project-2011-1-TR1-LE05-28151; 2011.

3. Republic of Turkey Ministry of Family Labour and Social Services, General Directory of Occupational Health and Safety. Information Card 2 (Safety construction): Working at Height, Basic Information.

4. Republic of Turkey Ministry of Family Labour and Social Services, General Directory of Occupational Health and Safety. Information Card 5 (Safety construction): Personal Protective Equipments against Falling.

5. Soydan AS and Kurbak A. Küçük çaplı yuvarlak tekstil malzemeleri ve üretim metodları (Small Diameter Circular Textile Materials and Their Manufacturing Methods). Tekstil ve Mühendis, 2010;17(80).

6. Teufelberger. Rope Constructions. [Document on the Internet]. [Cited 2020 September 17]. Available from: https://www.teufelberger.com/en/productsservices/safety-and-rescue-ropes/application-specific-menu-safety-and-rescueropes/technology/rope-constructions.html

7. McKenna HA, Hearle JWS and O'Hear N. Handbook of fibre rope technology. $1^{\text {st }}$ edition. Woodhead Publishing Limited, CRC Press, ISBN 185573606 3, 2004.

8. Teufelberger. Industrial Fiber Rope. [Cited 2017 March 19]. Available from: https://www.teufelberger.com/fileadmin/Teufelberger/downloads/15-09-

16_Industrial-Fiber-Rope_Web.pdf

9. Sailing Smacks-Rope. [Cited 2020 September 17]. Available from: http://www.smackdock.co.uk/rope.htm

10. Colorado Technical Rescue. Rope Rescue. [Cited 2017 March 19]. Available from: http://kristinandjerry.name/cmru/rescue_info/Colorado\%20Technical\%20Rescue\% 20School/Rope\%20Rescue.pdf

11. Chapter 2. Rope Properties. [Cited 2017 April 23]. Available from: https://vtechworks.lib.vt.edu/bitstream/handle/10919/30925/Chapter2.pdf?seque nce $=4$

12. HTMRI, 2004. Lesson 8: Rescue Equipment. [Cited 2017 April 17]. Available from: https://tools.niehs.nih.gov/wetp/public/Course_download2.cfm?tranid=4379

13. Certex. Fiber rope general information. [Cited 2017 February 19]. Available from: https://certex.com/wp-content/uploads/fiber-rope.pdf

14. XComposites. Braided textile composites, modelling procedure of braided composites. [Cited 2021 March 7]. Available from: https://www.xcomposites.com/braided.html

15. Balta C. 5 Kasım 2018. Yüksekte Çalışmalarda Lanyard Seçimi ve Kullanımı. [Cited 2021

March

7].

Available

from: 
https://www.hallmark.com.tr/post/y\%C3\%BCksekte\%C3\%A7al\%C4\%B1\%C5\%9Fmalarda-lanyard-se\%C3\%A7imi-vekullan\%C4\%B1m\%C4\%B1

16. XS Platforms. Fall restraint versus fall arrest lanyards. [Cited 2021 March 7]. Available from: https://fallprotectionxs.com/fall-arrest-versus-fall-restraint-lanyards/

17. Safety at Height. Personal Fall Protection Equipment. [Cited 2021 March 7]. Available from: https://www.safety-height.co.uk/products-services/personal-fallprotection/\#GettingTheCorrectEquipment

18. W.S. Safety. Fall Arrest vs. fall restraint-two types of height safety systems. [Cited 2021 March 7]. Available from: https://wssafety.com/posts/fall-arrest-vs-fallrestraint-two-types-of-height-safety-systems

19. Leading Edge. Fall Protection Lanyards. [Cited 2021 March 7]. Available from: https://www.leadingedgesafety.co.uk/blog/fall-protection-lanyards/

20. Personal Fall Restraint System Components. [Cited 2021 March 7]. Available from: https://ehs.yale.edu/sites/default/files/files/fall-restraint-components.pdf

21. At Height. Blaze double positioning lanyards. [Cited 2021 March 7]. Available from: http://www.at-height.com/Blaze-Double-Positioning-Lanyard_p_166.html

22. Teufelberger. Safety and Rescue Products. [Cited 2021 March 7]. Available from: https://www.teufelberger.com/pub/media/contentmanager/content/download s/5000003_20-06-16_Safety-Rescue-Catalog_EN_web.pdf

23. ARCO. ARCO Two Tails Fall Arrest Rope Lanyard ARCO material code - 4A0800. [Cited 2021 March 7]. Available from: https://www.arco.co.uk/103/content/factsheets/4A0800\%20ARC0\%20TWO\% 20TAILS\%20FALL\%20ARREST\%20ROPE\%20LANYARD.PDF

24. SafetyGearStore. Rope absorber lanyard (RAL) technical data sheet. [Cited 2021 March 7]. Available from: https://www.safetygearstore.co.uk/images/uploaded/RAL-IS4.pdf

25. Edelrid. Personal fall protection equipment, low stretch kernmantel rope, EN 1891. https://www.edelrid.de/en/knowledgebase/norms/pics/EN_1891_en.pdf?m=1564645041\&

26. Pelican Rope. 3 strand adjustable rope lanyard. [Cited 2020 February 12]. Available from: https://pelicanrope.com/3-strand-adjustable-rope-lanyard/

27. Pelican Rope. Adjustable safety lanyard, double braid. [Cited 2020 December 12]. Available from: https://www.ebay.com/itm/Pelican-Rope-LYB-160-07A-AdjustableSafety-Lanyard-Double-Braid-/184032484690

28. Ömeroğlu S. The effect of braiding parameters on the mechanical properties of braided ropes. Fibres and Textiles in Eastern Europe, 2006; 14(4): 53. 